\title{
WEATHER SENSITIVITY OF DOWNY MILDEW AND ALTERNARIA BLIGHT OF MUSTARD IN THE GANGETIC WEST BENGAL, INDIA
}

\author{
S Banerjee $^{1}$, I Bhattacharya ${ }^{2}$, S A Khan ${ }^{2}$ and AKS Huda ${ }^{3}$
}

\begin{abstract}
The infestation of disease-pest poses a considerable threat to rapeseed-mustard production in India. Alternaria blight [A. brassicicola (Schw.)] and downy mildew [Peronospora parasitica (Pers.) Kuntze] are the major diseases in lower Gangetic plains of India. As the rate of disease increase are dependent on weather factors, weather-based forewarning system may enable to guide farmers to take protection measures timely. The paper aims at to find the effect of weather on alternaria blight and downy mildew infestations. The weather data were compared with Percent Disease Index and the prevailing weather condition during peak disease intensity has been sorted out. It was observed that an increasing trend of last seven days average minimum temperature and relative humidity indicates more Alternaria blight and downy mildew infestation.
\end{abstract}

Key words: Mustard, Alternaria blight, Downy mildew, PDI, Temperature, RH

\section{INTRODUCTION}

Oilseed Brassicas are among the major oilseed crops cultivated in Indian subcontinent and India produces about $11.3 \%$ of the world's rapeseed-mustard (Damodaram and Hegde, 2002). Although the acreage under rapeseed-mustard is considerably high in India, its productivity is low due to several biotic and abiotic factors. Among these, the infestation of alternaria blight [A. brassicicola (Schw.)] and downy mildew [Peronospora parasitica (Pers.) Kuntze] play an important role in reducing the yield of mustard. Downy mildew along with white rust causes $37-47 \%$ fewer pod production and 17 - 32\% less seed in mustard (Bains and Jhooty, 1980) while alternaria blight reduces upto 35\% yield (Kolte et al., 1987). Infections of the diseases are dependent upon weather factors and suitable disease-weather relationship can be developed to assess the risk of the diseases (McDonald and Boland, 2004). The weather based modeling for early warning of pest/disease infestation may provide appropriate tool for predicting pest/disease status. (Agrawal et al., 2004). In this present investigation, a preliminary work was carried out to find the effect of weather on alternaria blight and downy mildew infestations so that their peak intensity can be predicted.

\section{MATERIALS AND METHODS}

The experiment was conducted at the University Farm of Bidhan Chandra Krishi Viswavidyalaya,

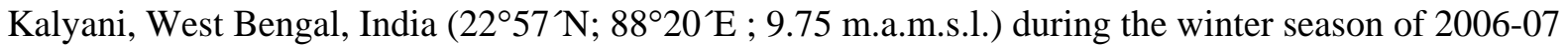
and 2007-08. The study area comes under sub-tropical humid climate having moderate summer and mild winter seasons. The soil of the experimental site is moderately well drained with sandy loam to clay texture.

The experiment was laid out in split-plot design with three replications. The main plots included two varieties of Indian mustard (Brassica juncea) viz., Varuna and Rohini and one variety of yellow sarson (Brassica campestris) viz., 'B-9' (termed as V1, V2 and V3 respectively), whereas sub-plots consisted of four dates of sowing (8 - 29 November 2006, at weekly interval, termed as D1, D2, D3 and D4). All the crops were sown with a seed rate of $7 \mathrm{~kg} \mathrm{ha}^{-1}$ in lines in well pulverized and level land, with an uniform spacing of $30 \mathrm{~cm}$ between the rows. Seven days after emergence additional plant population were uprooted to fix $10 \mathrm{~cm}$ spacing between the plants in each rows. Recommended

\footnotetext{
${ }^{1}$ AICRP on Agrometeorology, Directorate of Research, BCKV, Kalyani, Nadia: 741235, West Bengal, India.

${ }^{2}$ Faculty of Agriculture, Bidhan Chandra Krishi Viswavidyalaya, Mohanpur, Nadia: 741252, West Bengal, India.

${ }^{3}$ University of Western Sydney, Australia.
} 
dose of fertilizer was applied and crops under each dates of sowing received three irrigations at 25, 50 and 75 days after sowing. No fungicides were applied to the crop for controlling diseases. However insects were controlled with the help of metasystox (@2ml per litre of water).

From each plots five plants were selected at random and disease incidence of the said diseases were recorded at weekly interval throughout the crop growth period. The infestation of alterneria blight and downy mildew were rated on a 0 to 50 scale with a gap of 5 units (e.g., $0,5,10,15, \ldots, 50$ ). Leaves free from infection was rated as ' 0 ', while lesions coalease to form irregular and appears as a typical blight symptom covering $>50 \%$ leaf area was rated as ' 50 ' in case of alterneria blight. For downy mildew, the symptom of creamy white to light brown spots with cottony growth covering 25.1 to $50 \%$ leaf area was rated as ' 50 '. The Percent Disease Index (PDI) was worked out using the following formula (McKinney, 1923):

PDI = (Sum of all ratings X 100) / (Number of observations X Maximum disease rating)

Weather data with respect to maximum temperature, minimum temperature and relative humidity were recorded daily and averaged for last seven and fifteen days prior to disease observation. Simple correlation coefficient was obtained between average PDI and weather parameters.

\section{RESULTS AND DISCUSSION}

In case of downy mildew, irrespective of variety for almost all dates of sowing the highest intensity was observed during last week of January (Table 1). For D2 and D3 sown crop (crop which sown in mid November), the infestation was maximum. Varuna variety was mostly infested with downy mildew.

The average value of downy mildew intensity is positively, but not significantly correlated with maximum temperature, minimum temperature and relative humidity. The average values of last seven days minimum temperature [Min T (7)] and last fifteen days relative humidity [RH (15)] (prior to disease observation date) were better correlated with downy mildew intensity. The variation of the PDI values over crop growth season were plotted along with Min T (7) and RH (15) for both the years separately (Fig. 1and 2).

It is observed that when the magnitude of Min T (7) and RH (15) shows an increasing rate and the values are around $10^{\circ} \mathrm{C}$ and $46 \%$ respectively, the intensity of down mildew in the Gangetic West Bengal increases. Observation on daily weather data revealed that the peak downy mildew intensity was observed when:

Maximum temperature: Greater than $27^{\circ} \mathrm{C}$

Minimum temperature: Greater than $10^{\circ} \mathrm{C}$

Relative humidity: Around $100 \%$ in the morning and $50 \%$ in the afternoon

Likewise the effect of dates of sowing on per cent disease index of alternaria blight of different varieties of rape and mustard was also evaluated. It was observed that the percent disease index (PDI) of alternaria blight was highest in the crop sown 8 November and with delay in sowing beyond this date, the PDI decreased. The times for incidence of the highest PDI among all the varieties varied from 26 January to 7 February. The progress of PDI with time did not follow an increasing trend.

The varietal difference with regard to PDI showed that the highest PDI was found in V1 followed by V2 and V3. It was interesting to note that among the varieties undertaken in the present study, the highest PDI appeared always on 30 January (Table 2).

Figure 3 and 4 show the variation of alternaria blight intensity and meteorological parameters over crop growth seasons of 2006-07 and 2007-08. The average values of last seven days minimum temperature [Min T (7)] and last seven days relative humidity [RH (15)] (prior to disease observation date) were better correlated with alternaria blight intensity. Hence they are shown in the figures. The figures reveal that when $\mathrm{RH}$ and minimum temperature show an increasing rate, the alternaria blight intensity is also increasing.

\section{CONCLUSION}


Ultimately, it can be concluded that the attack of downy mildew is more in late sown crop whereas the attack of alternaria blight is more in early sown crop. The minimum temperature and relative humidity increase is an indication of increase of both the diseases.

\section{REFERENCES}

Agrawal, Ranjana, Mehta, S.C., Kumar, Amrender and Bhar, L.M. 2004. Development of weather based forewarning system for crop pests and diseases. Project Report, IASRI, New Delhi Mission mode project under NATP, PI, Dr. Y.S. Ramakrishna, CRIDA, Hyderabad.

Bains, S. S. and Jhooty, J. S. 1980. Mixed infections by Albugo candida and Peronospora parasitica on Brassica juncea inflorescence and their control. Indian Phytopathol. 32(2): 268-271.

Damodaram, T., Hegde, D.M., 2002. Oilseeds Situation: A Statistical Compendium 2002. Directorate of Oilseeds Research, Hyderabad: 500030, India $471 \mathrm{pp}$.

Kolte SJ, Awasthi RD and Viswanath, V. 1987. Assessment of yield losses due to Alternaria blight in rapeseed and mustard. Indian Phytopathol., 40(2): 209-211.

McDonald, M. R. and Boland, G. J. 2004. Forecasting diseases caused by Sclerotinia spp. in eastern Canada: fact or fiction? Can. J. Plant Pathol., 26: $480-488$.

McKinney, H. N. 1923. Influence of soil temperature and moisture on infection of wheat seedlings by Helmenthosporium sativum. J. Agric. Research. 26: 195 - 207.

Table 1: Effect of date of sowing and variety on downy mildew intensity for 2006 sown crop

\begin{tabular}{|c|c|c|c|c|c|c|c|c|c|c|}
\hline & \multicolumn{10}{|c|}{ Date of observation } \\
\hline & 12.12 .06 & 19.12.06 & 26.12 .06 & 2.1.07 & 12.1.07 & 16.1.07 & 26.1.07 & 30.1 .07 & 7.2.07 & $\begin{array}{l}13.2 \\
07\end{array}$ \\
\hline \multicolumn{11}{|c|}{ Date of sowing } \\
\hline D1 & 8.1 & 6.0 & 9.0 & 21.2 & 23.7 & 20.0 & 33.0 & 27.2 & 28.7 & 28.3 \\
\hline D2 & 0.0 & 1.6 & 10.6 & 17.6 & 19.1 & 19.6 & 27.1 & 30.5 & 31.2 & 26.6 \\
\hline D3 & 0.0 & 1.1 & 9.3 & 14.4 & 12.7 & 15.6 & 25.7 & 30.5 & 25.3 & 19.0 \\
\hline D4 & 0.0 & 0.5 & 6.5 & 8.6 & 8.9 & 15.2 & 23.1 & 27.0 & 27.6 & 23.3 \\
\hline $\operatorname{SEm}( \pm)$ & 0.2 & 0.2 & 0.2 & 0.3 & 0.5 & 0.5 & 0.7 & 2.0 & 0.3 & 0.4 \\
\hline CD & 0.9 & 0.8 & 0.7 & 1.4 & 1.8 & 1.9 & 2.6 & NS & 1.3 & 1.4 \\
\hline \multicolumn{11}{|l|}{ Variety } \\
\hline V1 & 1.8 & 1.1 & 6.7 & 12.5 & 12.7 & 13.9 & 23.4 & 26.3 & 31.2 & 28.4 \\
\hline V2 & 2.0 & 1.9 & 6.4 & 11.6 & 12.3 & 13.3 & 24.5 & 22.5 & 28.5 & 31.8 \\
\hline V3 & 2.3 & 3.9 & 13.5 & 22.3 & 23.4 & 25.7 & 33.8 & 37.6 & 24.9 & 12.8 \\
\hline $\operatorname{SEm}( \pm)$ & 0.0 & 0.0 & 0.1 & 0.2 & 0.3 & 0.3 & 0.4 & 1.8 & 0.6 & 0.5 \\
\hline CD & -- & 0.1 & 0.2 & 0.7 & 0.8 & 0.9 & 1.3 & 5.5 & 1.8 & 1.6 \\
\hline \multicolumn{11}{|c|}{ Interaction ( D x V) } \\
\hline $\operatorname{SEm}( \pm)$ & 0.0 & 0.0 & 0.1 & 0.4 & 0.5 & 0.5 & 0.8 & 3.2 & 1.1 & 0.9 \\
\hline CD & -- & 0.1 & 0.6 & 1.9 & 2.0 & 2.4 & 3.5 & NS & 4.8 & 4.2 \\
\hline
\end{tabular}


Table 2: Effect of date of sowing and variety on Alternaria blight intensity for 2006 sown crop

\begin{tabular}{|c|c|c|c|c|c|c|c|c|c|c|}
\hline \multicolumn{11}{|c|}{ Date of observation } \\
\hline \multicolumn{2}{|c|}{12.12 .06} & 19.12 .06 & 26.12 .06 & 2.1 .07 & 12.1 .07 & 16.1 .07 & 26.1 .07 & 30.1 .07 & 7.2 .07 & 13.2 .07 \\
\hline \multicolumn{11}{|c|}{ Date of sowing } \\
\hline D1 & 6.9 & 0.6 & 5.14 & 7.85 & 12.74 & 22.58 & 37.40 & 36.63 & 38.73 & 35.83 \\
\hline D2 & 0.0 & 0.0 & 3.30 & 6.80 & 11.79 & 18.68 & 33.33 & 39.60 & 40.77 & 30.73 \\
\hline D3 & 0.0 & 0.1 & 2.29 & 10.34 & 8.53 & 15.07 & 30.17 & 34.80 & 17.83 & 13.77 \\
\hline D4 & 0.0 & 0.0 & 0.37 & 3.41 & 4.12 & 14.19 & 27.67 & 27.52 & 20.26 & 9.67 \\
\hline $\operatorname{SEm}( \pm)$ & 0.1 & 0.1 & 0.05 & 0.26 & 0.26 & 0.31 & 0.31 & 0.52 & 0.55 & 0.50 \\
\hline CD & 0.2 & 0.2 & 0.19 & 1.02 & 1.00 & 1.24 & 1.24 & 2.05 & 2.16 & 1.98 \\
\hline \multicolumn{11}{|l|}{ Variety } \\
\hline V1 & 1.5 & 0.0 & 1.85 & 3.17 & 7.76 & 18.43 & 38.13 & 41.47 & 35.12 & 28.30 \\
\hline V2 & 1.7 & 0.2 & 1.69 & 5.55 & 6.67 & 14.92 & 30.80 & 33.42 & 28.30 & 30.85 \\
\hline V3 & 2.0 & 0.3 & 4.80 & 12.59 & 13.46 & 19.54 & 27.50 & 29.03 & 24.78 & 8.35 \\
\hline $\operatorname{SEm}( \pm)$ & 0.4 & 0.4 & 0.44 & 0.34 & 0.34 & 0.45 & 0.45 & 0.50 & 0.57 & 0.65 \\
\hline CD & NS & NS & 1.30 & 1.02 & 1.01 & 1.35 & 1.35 & 1.50 & 1.69 & 1.94 \\
\hline \multicolumn{11}{|c|}{ Interaction ( $\mathrm{D} \times \mathrm{V}$ ) } \\
\hline $\operatorname{SEm}( \pm)$ & 0.8 & 0.8 & 0.76 & 0.60 & 0.59 & 0.79 & 0.79 & 0.87 & 0.99 & 1.13 \\
\hline CD & NS & NS & NS & 2.68 & 2.65 & 3.54 & 3.54 & 3.93 & NS & 5.09 \\
\hline
\end{tabular}

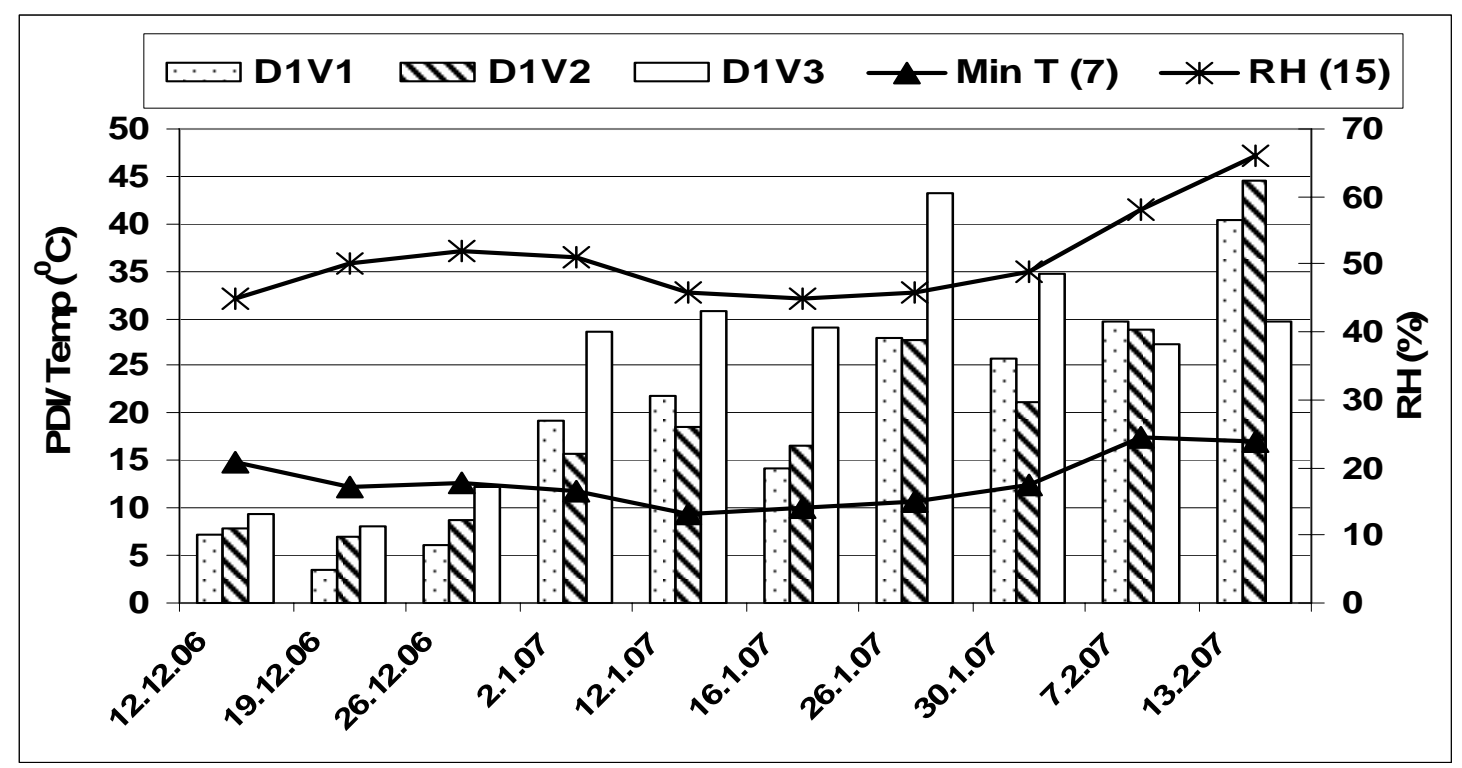

Fig. 1. Variation of PDI of downy mildew along with last seven days average minimum temperature [min T (7)] and last fifteen days average relative humidity [RH (15)] for 2006 sown crop 


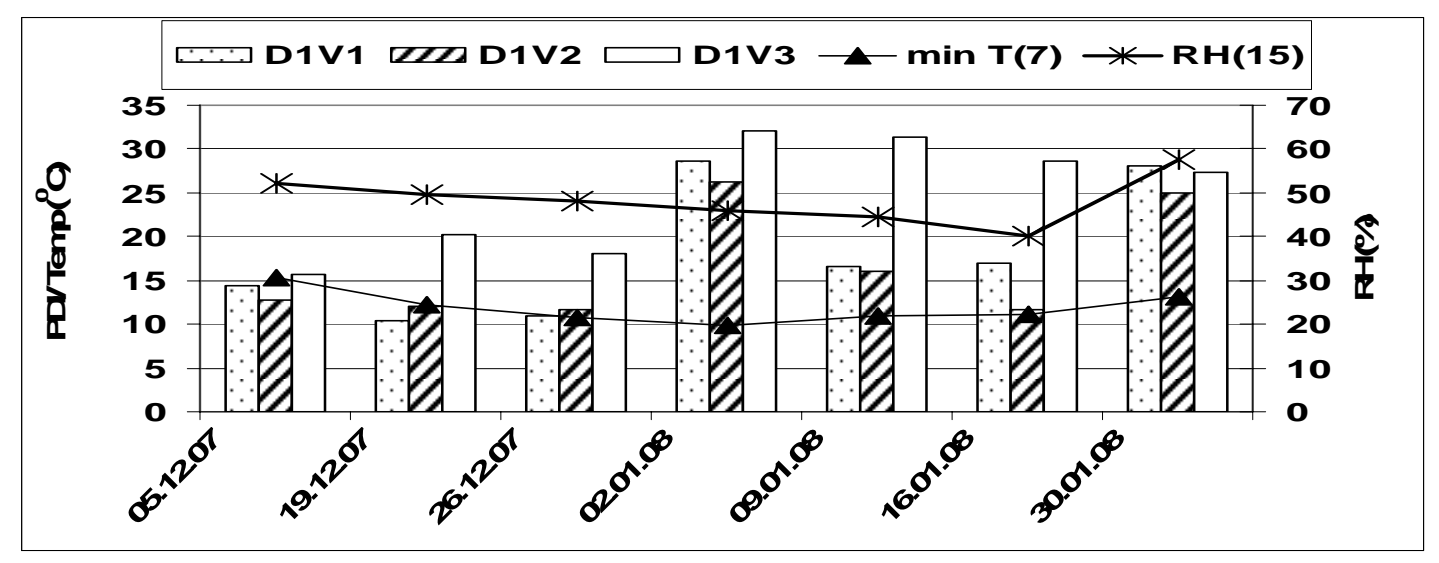

Fig. 2. Variation of PDI of downy mildew along with last seven days average minimum temperature [min T (7)] and last fifteen days average relative humidity [RH (15)] for 2007 sown crop

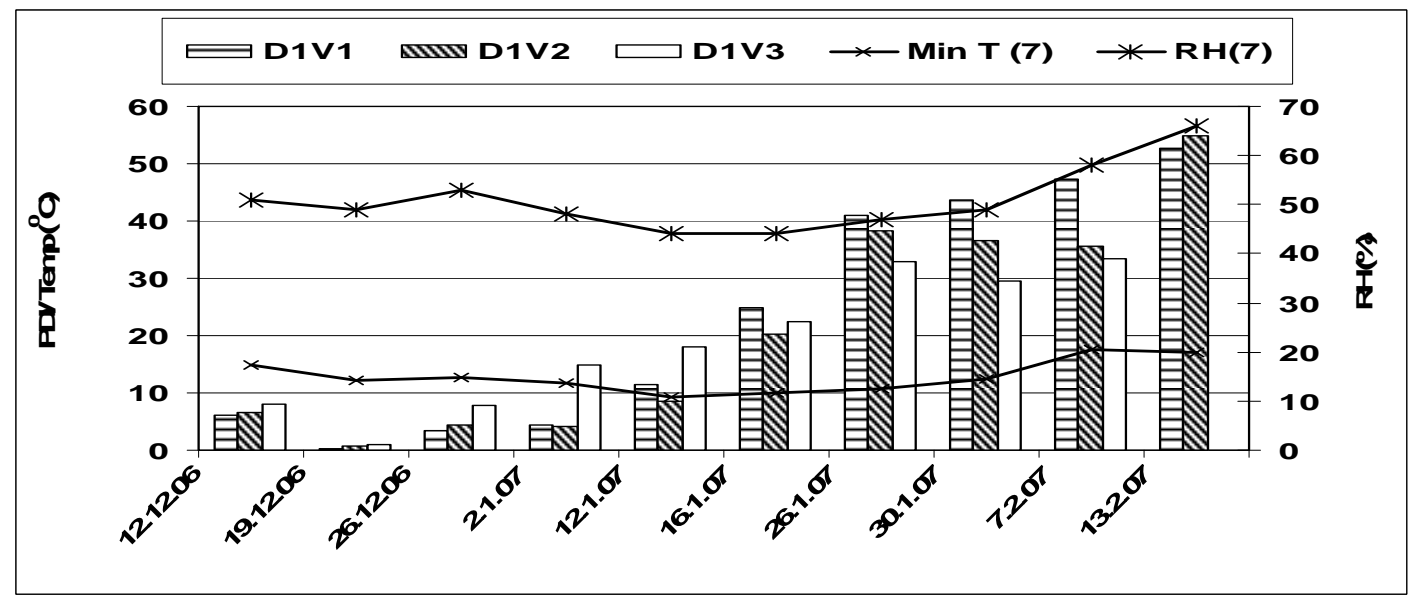

Fig. 3. Variation of PDI of alternaria blight along with last seven days average minimum temperature [min T (7)] and last seven days relative humidity [RH (7)] for 2006 sown crop

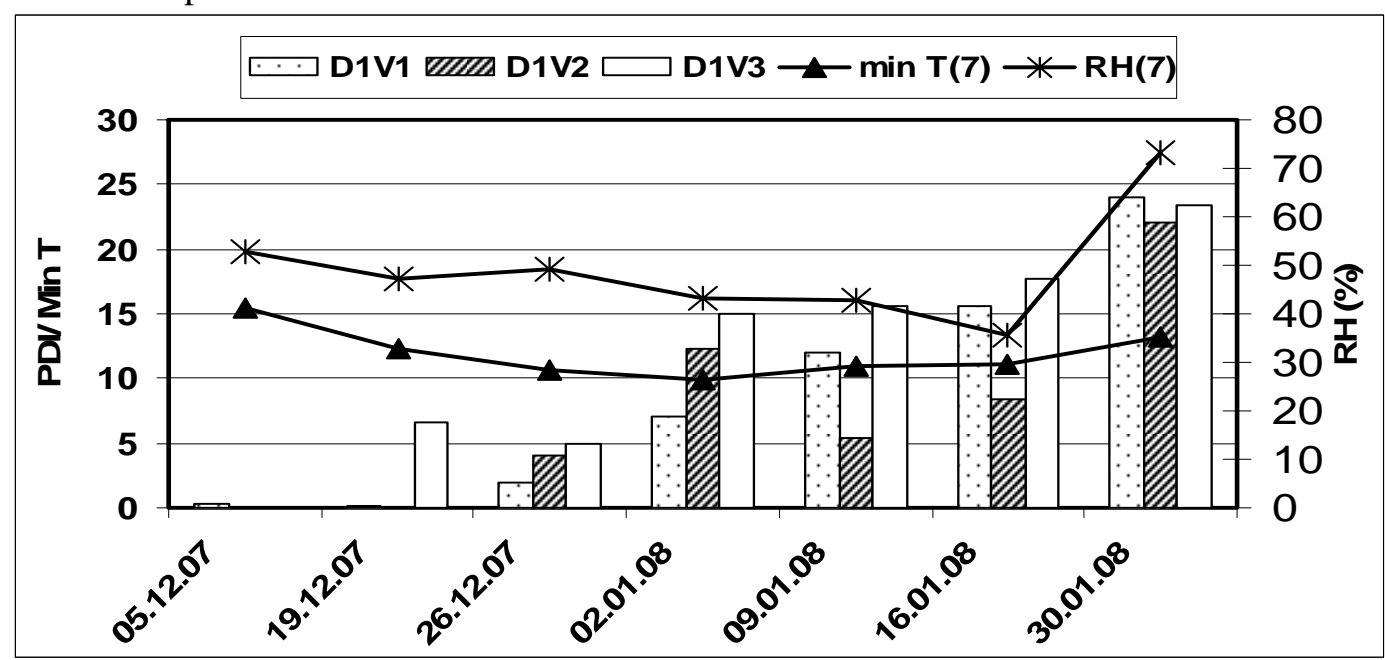

Fig. 4. Variation of PDI of alternaria blight along with last seven days average minimum temperature [min T (7)] and last seven days relative humidity [RH (7)] for 2007 sown crop 